\title{
ISUE AKSESIBILITAS DAN PENGEMBANGAN WILAYAH SEBAGAI KRITERIA PENENTU PRIORITAS PENINGKATAN JALAN DI KABUPATEN PIDIE JAYA
}

\author{
Ahmad Irvan Antony Has ${ }^{1)}$, Renni Anggraini ${ }^{2)}$, Alfa Taras Bulba ${ }^{3)}$ \\ ${ }^{1}$ Magister Teknik Sipil Fakultas Teknik Universitas Syiah Kuala \\ ${ }^{2,3}$ Jurusan Teknik Sipil Fakultas Teknik Universitas Syiah Kuala \\ Jl Syekh Abdurrauf No. 7, Kopelma Darussalam, Banda Aceh, 23111 \\ Email:airvan3@gmail.com ${ }^{1)}$, renni.anggraini@gmail.com ${ }^{2)}$, \\ alfatarasbulba@unsyiah.ac.id ${ }^{3}$
}

DOI: http://dx.doi.org/10.29103/tj.v11i1.460

(Received: December 2020 / Revised: January 2021 / Accepted: January 2021)

\begin{abstract}
Abstrak
Dinas Pekerjaan Umum (PU) Kabupaten Pidie Jaya pada tahun 2020 mengajukan usulan peningkatan ruas jalan sebanyak 5 ruas kepada Kementerian Pekerjaan Umum dan Perumahan Rakyat (PUPR) melalui Dana Alokasi Khusus (DAK) yang akan dilaksanakan pada tahun 2021. Tujuan dari penelitian ini untuk menganalisis urutan prioritas peningkatan ruas jalan di Kabupaten Pidie Jaya berdasarkan criteria aksesibilitas dan pengembangan wilayah. Data yang digunakan pada penelitian ini berupa data primer dan data sekunder. Metode pengumpulan data primer menggunakan pendekatan kuantitatif melalui kuesioner dan data sekunder didapatkan melalui instansi Pemerintah Kabupaten Pidie Jaya. Penetapan responden pada penelitian ini menggunakan teknik purposive sampling, dan ditetapkan sebanyak 5 responden, yaitu KepalaBidang Bina Marga Dinas PU Kabupaten Pidie Jaya, Kepala Bidang Perencanaan Sarana dan Prasarana Badan Perencanaan Pembangunan Daerah (Bappeda) Kabupaten Pidie Jaya, Kepala Bidang Perhubungan Jalur Darat Dinas Perhubungan Kabupaten Pidie Jaya, Anggota Komisi D Bidang Pembangunan Dewan Perwakilan Rakyat Kabupaten (DPRK) Pidie Jaya, dan Akademisi Universitas Syiah Kuala. Kriteria aksesibilitas dan pengembangan wilayah akan menjadi pertimbangan dalam menentukan urutan prioritas 5 (lima) alternativ ruas jalan yang akan ditingkatkan. Untuk menentukan bobot kriteria dan bobot alternative berpasangan digunakan metode Analytical Hierarchy Process (AHP), selanjutnya persamaan matematika digunakan untuk mendapatkan urutan prioritas peningkatan jalan. Berdasarkan hasil analisis data menunjukkan bahwa criteria aksesibilitas lebih dominan. Urutan prioritas peningkatan ruas jalan berdasarkan criteria aksesibilitas dan pengembangan wilayah menunjukkan bahwa alternatif Jalan Simpang PertanianCot Trieng - Rungkom sebagai prioritas pertama, dan alternatif Jalan Trienggadeng Panton Beurasan-Cubo sebagai prioritas kedua.
\end{abstract}

Kata kunci: prioritas, jalan,kriteria, aksesibilitas, pengembangan wilayah

\begin{abstract}
The Public Works Office (PekerjaanUmum (PU)) of Pidie Jaya Regency in 2020 has submitted a proposal to increase the road section of 5 sections to the Ministry of Public Works and Public Housing (PUPR) through a Special Allocation Fund (DAK), which will be implemented in 2021. The purpose of this study is to analyze the
\end{abstract}

Isue Aksesibilitas dan Pengembangan Wilayah Sebagai Kriteria Penentu Prioritas Peningkatan Jalan di Kabupaten Pidie Jaya - Ahmad Irvan Antony Has, Renni Anggraini, Alfa Taras Bulba 
priority order of segment improvement. Roads in Pidie Jaya Regency based on accessibility criteria and regional development. The data used in this study are primary data and secondary data. The primary data method used a quantitative approach to a questionnaire and the data were obtained through the Pidie Jaya district government agencies. Determination of respondents in this study using purposive sampling technique, and determined as many as 5 respondents, namely the Head of Bina Marga Division of the Public Works Agency of Pidie Jaya Regency, Head of the Planning for Facilities and Infrastructure of the Regional Development Planning Agency (Bappeda), Pidie Jaya Regency, Head of the Landline Transportation Department Pidie Jaya District Transportation, Members of Commission D for the Development Sector of the District People's Representative Council (DPRK) Pidie Jaya, and academics at Syiah Kuala University. The criteria for accessibility and regional development will be considered in determining the priority order of 5 (five) alternative roads to be improved. The Analytical Hierarchy Process (AHP) method is used to determine the criteria weights and the paired alternative weights. Mathematical equations are used to obtain the priority order of road improvement. Based on the results of data analysis, it shows that the accessibility criteria are more dominant. The order of priority for road improvement based on accessibility criteria and regional development shows that the alternative for the SimpangPertanian - Cot Trieng - Rungkom Road is the first priority, and the Trienggadeng - Panton Beurasan Cubo road alternative is the second priority.

Keywords: priority,road, criteria, accessibility, regional development

\section{Latar Belakang}

Jalan merupakan prasarana transportasi yang meliputi segala bagian jalan termasuk bangunan pelengkap dan perlengkapannya yang diperuntukkan bagi lalu lintas, yang berada di atas permukaan tanah, di bawah permukaan tanah dan/atau air, serta di atas permukaan air. Jalan mempunyai peranan penting dalam kehidupan sehari-hari terutama yang menyangkut perwujudan perkembangan antar wilayah yang seimbang, pemerataan hasil pembangunan serta pemantapan pertahanan dan keamanan untuk mewujudkan pembangunan nasional. Penyelenggaraan jalan yang konsepsional dan menyeluruh perlu melihat jalan sebagai suatu kesatuan system jaringan jalan yang mengikat dan menghubungkan pusat-pusat kegiatan (Pemerintah Republik Indonesia, 2006). Sehubungan pentingnya peranan jalan, maka pemerintah perlu melakukan kegiatan peningkatan jalan demi terwujudnya pemerataan pembangunan daerah dan lancarnya pertumbuhan ekonomi. Peningkatan jalan adalah salah satu kegiatan penanganan jalan untuk meningkatkan struktur dan kapasitas jalan hingga mempunyai kondisi yang mantap. Prasarana jaringan jalan yang baik akan dapat meningkatkan aksesibiltas dan mobilitas masyarakat, sehingga jangkauan terhadap berbagai kebutuhan ekonomi maupun social dapat terpenuhi dengan baik (Afriansyah et al., 2012).

Pada tahun 2020, Dinas Pekerjaan Umum (PU) Kabupaten Pidie Jaya mengajukan usulan peningkatan ruas jalan sebanyak 5 ruas kepada Kementrian Pekerjaan Umum dan Perumahan Rakyat (PUPR) melalui Dana Alokasi Khusus (DAK) yang akan dilaksanakan pada tahun 2021 (Dinas Pekerjaan Umum Kabupaten Pidie Jaya, 2020).Adapun 5 ruas jalan yang diusulkan pada Dana Alokasi Khusus tahun 2020 merupakan hasil survey tahunan berkala Dinas Pekerjaan Umum (PU) Kabupaten Pidie Jaya yang persentase kondisi tidak

Isue Aksesibilitas dan Pengembangan Wilayah Sebagai Kriteria Penentu Prioritas Peningkatan Jalan di Kabupaten Pidie Jaya - Ahmad Irvan Antony Has, Renni Anggraini, Alfa Taras Bulba 
mantap atau kritis tertinggi, yaitu Jalan Blang Dalam-Jurong Teungoh, Jalan Jeulanga Barat-Jeulanga Mata Ie, Jalan SimpangPertanian-Cot Trieng-Rungkom, Jalan Trienggadeng-Panton Beurasan-Cubo, dan Jalan Meurandeh Alue-Asan Kumbang-Blang Miroe.

Kriteria yang ditentukan dalam penelitian ini adalah aksesibilitas dan pengembangan wilayah, menurut Qanun Rencana Pembangunan JangkaMenengah (RPJM) Kabupaten Pidie Jaya 2019-2024 faktor aksesibilitas dan pengembangan wilayah merupakan isue dan permasalahan strategis yang harus segera diselesaikan agar dapat tercapainya pemerataan pembangunan daerah dan memicu pertumbuhan ekonomi (Pemerintah Kabupaten Pidie Jaya).Aksesibilitas merupakan daya tarik yang ditentukan oleh kemudahan dalam pencapaian keberbagai pusat kegiatan seperti pusat perdagangan, pusat pendidikan, daerah industri, jasa pelayanan perbankan, tempat rekreasi, pelayanan pemerintahan, jasa profesional, dan bahkan perpaduan antara semua kegiatan tersebut (S. Fatimah, 2019). Pengembangnan wilayah adalah pemerataan pengembangan antar wilayah baik secara fisik maupun social ekonomi wilayah (A.K. Mahi, 2016).Setiap kriteria yang ditentukan memiliki karakteristik yang berbeda terhadap ruas jalan yang diusulkan. Metode system pengambilan keputusan yang digunakan untuk menentukan urutan prioritas peningkatan jalan adalah Analytic Hierarchy Process (AHP). Dari hasil analisis yang dilakukan, maka dapat memudahkan stakeholders dalam penentuan urutan peningkatan ruas jalan di Kabupaten Pidie Jaya dengan mengedepankan isue - isue yang ada di dalam RPJMK Pidie Jaya. Adapun tujuan dari penelitian ini untuk mengetahui criteria dominan dan penentuan urutan prioritas peningkatan jalan di Kabupaten Pidie Jaya.

\section{Metode Penelitian}

Penentuan lokasi pada penelitian ini berdasarkan rencana usulan Dana AlokasiKhusus (DAK) Kabupaten Pidie Jaya tahun 2020 yang mengusulkan 5 ruas jalan untuk ditingkatkan di 3 kecamatan berbeda. Sumber data yang digunakan berupa data primer dan data sekunder. Data primer diperoleh melalui penyebaran kuesioner dan mendatangi langsung keberadaan responden atau stakeholder. Penentuan responden sebanyak 5 stakeholders ditentukan dengan menggunakan teknik purposive sampling. Adapun stakeholder yang ditetapkan sebagai responden adalah Kepala Bidang Bina Marga Dinas PU Kabupaten Pidie Jaya, Kepala Bidang Perencanaan Sarana dan Prasarana Badan Perencanaan Pembangunan Daerah (Bappeda) Kabupaten Pidie Jaya, Kepala Bidang Perhubungan Jalur Darat Dinas Perhubungan Kabupaten Pidie Jaya, Anggota Komisi D Bidang Pembangunan Dewan Perwakilan Rakyat Kabupaten (DPRK) Pidie Jaya, dan Akademisi Universitas Syiah Kuala. Sedangkan data sekunder yang digunakan adalah data rencana usulankegiatan DAK tahun 2020, data aksesibilitas dan pengembangan wilayah yang di peroleh dari Badan Statistik Kabupaten Pidie Jaya. Kemudian dilakukan penentuan urutan prioritas peningkatan ruas jalan berdasarkan aksesibilitas dan pengembangan wilayah dengan menggunakan metode Analytical Hierarchy Process (AHP). Hasil dari analisis pembobotan akan diurutkan dari nilai bobot tertinggi hingga bobot terendah.

Isue Aksesibilitas dan Pengembangan Wilayah Sebagai Kriteria Penentu Prioritas Peningkatan Jalan di Kabupaten Pidie Jaya - Ahmad Irvan Antony Has, Renni Anggraini, Alfa Taras Bulba 


\subsection{ObjekPenelitian}

Lokasi objek penelitian ini berada di Kabupaten Pidie Jaya Provinsi Aceh. Berdasarkan data usulan rencana kegiatan Dana Alokasi Khusus (DAK) Kabupaten Pidie Jaya pada tahun 2020 peningkatan 5 ruas jalan terbagi di 3 (tiga) kecamatan yang berbeda, yaitu Kecamatan Bandar Dua, Meureudu dan Trienggadeng. Lokasi objek penelitianini dapat dilihat pada gambar 1.

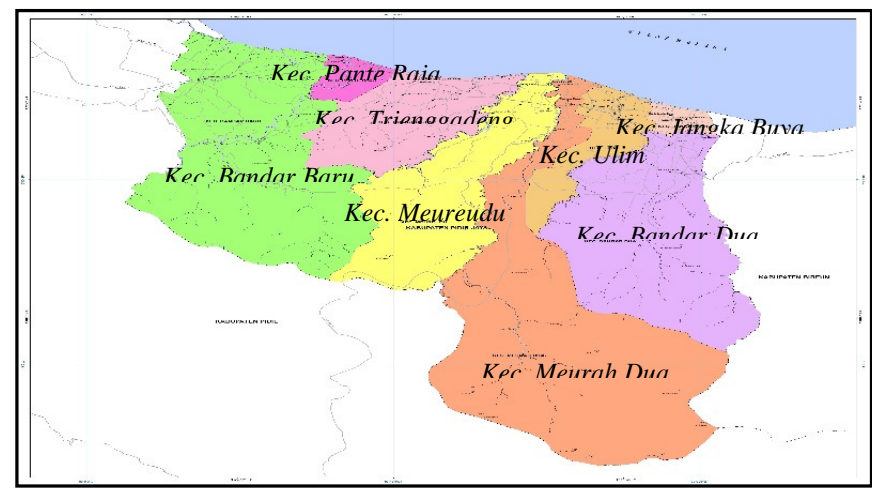

Gambar 1 Lokasi penelitian di Wilayah Administrasi Kabupaten Pidie Jaya

Ruas jalan yang diusulkan peningkatannya melalui DAK Kabupaten Pidie Jaya dapat dilihat pada Tabel 1.

Tabel 1 Objek penelitian

\begin{tabular}{llcc}
\hline No. & \multicolumn{1}{c}{ Nama Jalan } & Panjang & $\begin{array}{c}\text { Lokasi / } \\
\text { Kecamatan }\end{array}$ \\
\hline 1. & Jalan BlangDalam - Jurong Teungoh (A1) & $1.00 \mathrm{~km}$ & Bandar Dua \\
\hline 2. & Jalan Jeulanga Barat - Jeulanga Mata Ie (A2) & $1.02 \mathrm{~km}$ & Bandar Dua \\
\hline 3. & $\begin{array}{l}\text { Jalan SimpangPertanian - Cot Trieng- } \\
\text { Rungkom (A3) }\end{array}$ & $0.75 \mathrm{~km}$ & Meureudu \\
\hline 4. & $\begin{array}{l}\text { Jalan Trienggadeng - Panton Beurasan-Cubo } \\
\text { (A4) }\end{array}$ & $1.80 \mathrm{~km}$ & Trienggadeng \\
\hline 5. & $\begin{array}{l}\text { Jalan MeurandehAlue - Asan Kumbang - } \\
\text { BlangMiroe (A5) }\end{array}$ & $0.45 \mathrm{~km}$ & Bandar Dua \\
\hline
\end{tabular}

\subsection{Teknik Penentuan Sampel}

Teknik penentuan sampel yang digunakana dalah purposive sampling. Purposive sampling adalah teknik pengambilan sampel dengan pertimbangan tertentu (Ulwan, 2014). Sampel yang ditentukan adalah pemangku kepentingan dan pengambil kebijakan (stakeholders) yang mengetahui kondisi kriteria pada lokasi usulan peningkatan jalan di Kabupaten Pidie Jaya.

\subsection{Teknik Pengolahan Data}

Pengolahan data merupakan proses pengelolaan data secara terukur sebelum dilakukan analisis data. Pengukur jawaban persepsi responden menggunakan skala perbandingan (Saaty, 1993). Pengolahan data dalam penelitian ini melakukan tabulasi rekapitulasi jawaban kuesioner perbandingan criteria berpasangan dan perbandingan alternative berpasangan dari responden yang

Isue Aksesibilitas dan Pengembangan Wilayah Sebagai Kriteria Penentu Prioritas Peningkatan Jalan di Kabupaten Pidie Jaya - Ahmad Irvan Antony Has, Renni Anggraini, Alfa Taras Bulba 
berjumlah 5 (lima) orang. Perbandingan antar criteria dimaksudkan untuk menentukan bobot untuk masing-masing kriteria. Disisi lain, perbandingan antar pilihan untuk setiap criteria dimaksudkan untuk melihat bobot suatu pilihan dalam suatu kriteria. Dengan kata lain, penilaian ini dimaksudkan untuk melihat seberapa penting suatu pilihan dilihat dari criteria tertentu (Irawan et al., 2016).

\subsection{Teknik Analisis Data}

Metode analisis data yang digunakan untuk menjawab rumusan masalah pada penelitian ini adalah metode AHP suatu metode pengambilan keputusan dari berbagai masalah multi kriteria. Metode AHP ini menentukan prioritas dari berbagai alternative dengan memberikan nilai pada setiap alternative untuk setiap kriteria. Dalam penggunaan metode ini hal penting yang dibutuhkan adalah suatu struktur hierarki untuk memodelkan suatu permasalahan yang ada, di mana dalam permodelannya faktor-faktor yang mempengaruhi secara umum berada pada tingkat atas hierarki, dan faktor-faktor khusus berada di tingkat yang lebih rendah. Dalam prosesnya, metode ini menggunakan perbandingan berpasangan sederhana yang kemudian digunakan untuk mengembangkan prioritas keseluruhan untuk menentukan peringkat (Sushera et al., 2019). Menurut (Agus Taufik Mulyono, 2010), beberapa prinsip dasar AHP yaitu;

a. Decomposition

Decomposition adalah suatu upaya memecahkan atau mengelompokkan masalah yang rumit atau utuh menjadi kelompok-kelompok dalam bentuk hirarki proses pengambilan keputusan, di mana setiap kelompok atau elemen saling berhubungan.

b. ComparativeJudgment

Setelah masalah terdekomposisi, maka dua tahap penilaian atau membandingkan antar elemen yaitu perbandingan antar kriteria dan perbandingan antar pilihan untuk setiap kriteria. Perbandingan antar criteria dimaksudkan untuk menentukan bobot pada masing-masing kriteria.Disisi lain, perbandingan antar pilihan untuk setiap criteria dimaksudkan untuk melihat bobot suatu pilihan dalam suatu kriteria.

Tabel 2 Skala perbandingan

\begin{tabular}{|c|c|c|}
\hline $\begin{array}{l}\text { Tingkat } \\
\text { Kepentingan }\end{array}$ & Definisi & Keterangan \\
\hline 1 & Sama pentingnya & Kedua elemen mempunyai pengaruh sama \\
\hline 3 & $\begin{array}{l}\text { Sedikit lebih } \\
\text { penting }\end{array}$ & $\begin{array}{l}\text { Pengalaman dan penilaian sedikit menyokong satu } \\
\text { elemen dibandingkan dengan elemen lainnya }\end{array}$ \\
\hline 5 & Lebih penting & $\begin{array}{l}\text { Pengalaman dan penilaian sangat kuat menyokong satu } \\
\text { elemen dibandingkan dengan elemen lainnya }\end{array}$ \\
\hline 7 & Sangat penting & $\begin{array}{l}\text { Satu elemen yang kuat dikosongkan dominan terlihat } \\
\text { dalam praktek }\end{array}$ \\
\hline 9 & $\begin{array}{l}\text { Mutlak lebih } \\
\text { penting }\end{array}$ & $\begin{array}{l}\text { Satu elemen terbukti mutlak lebih disukai dibandingkan } \\
\text { pasangannya pada tingkat keyakinan tinggi }\end{array}$ \\
\hline $2,4,6,8$ & Nilai tengah & $\begin{array}{l}\text { Diberikan apabila ada } 2 \text { (dua) kompromi diantara } 2 \\
\text { (dua) pilihan }\end{array}$ \\
\hline aji/aij & Kebalikan & $\begin{array}{l}\text { Diberikan apabila elemen pada kolom "j” lebih disuk } \\
\text { dibandingkan dengan elemen pasangannya }\end{array}$ \\
\hline
\end{tabular}

Isue Aksesibilitas dan Pengembangan Wilayah Sebagai Kriteria Penentu Prioritas Peningkatan Jalan di Kabupaten Pidie Jaya - Ahmad Irvan Antony Has, Renni Anggraini, Alfa Taras Bulba 
Penilaian ini dimaksudkan untuk melihat seberapa penting suatu pilihan dilihat dari criteria tertentu. Nilai dan definisi pendapat kualitatif dalam skala perbandingan (Saaty, 1993), seperti pada Tabel 2.

c. Synthesisof Priority

Tahapan ini mengambil setiap turunan skala rasio prioritas prioritas local dalam berbagai level dari suatu hierarki dan menyusun suatu komposisi global dari kumpulan prioritas untuk elemen-elemen dalam hierarki terbawah. Dalam penilaian ini dilakukan untuk setiap sel dalam matriks perbandingan maka akan didapatkan suatu matriks perbandingan baru yang merupakan matriks perbandingan gabungan semua responden sehingga didapatkan eigen vector untuk masing-masing criteria dengan menggunakan persamaan:

$$
W_{i}=\sqrt[n]{\left(a_{i 1} x a_{i 2} x a_{i 3} \ldots \ldots . . x a_{i n}\right.}
$$

Matriks yang diperoleh merupakan eigen vector yang juga menjadi bobot criteria atau eigen vector yaitu $(\mathrm{Xi})$ ditentukan berdasarkan persamaan:

$$
X_{i}=\frac{W i}{\sum W i}
$$

Nilai eigen value yang terbesar ( $\lambda$ maks), didapatkan dari persamaan:

$$
\lambda_{\text {maks }}=\sum \text { aij } x X j
$$

d. Logical Consistency

Tahapan ini melakukan penilaian intensitas hubungan diantara elemen-elemen yang didasarkan pada suatu criteria khusus yang telah menjustifikasi satu sama lain dalam cara-cara yang logis. Pengukuran konsistensi dari suatu matriks didasarkan pada suatu eigen value maksimum, sehingga inkonsistensi yang biasa dihasilkan matriks perbandingan dapat diminimalkan yang dihitung dengan persamaan:

$$
C I=\frac{\lambda_{\text {maks }}-n}{n-1}
$$

Matrik random dengan skala penilaian 1 sampai dengan 9 beserta kebalikannya sebagai Random Indeks (RI). Dengan Random Indeks (RI) setiap ordo matriks seperti Tabel 3 .

Tabel 3 Random Indeks

\begin{tabular}{ccccccccccccccc}
$\begin{array}{c}\text { Ukuran } \\
\text { Matriks (n) }\end{array}$ & 1,2 & 3 & 4 & 5 & 6 & 7 & 8 & 9 & 10 & 11 & 12 & 13 & 14 & 15 \\
\hline Nilai RI & 0,00 & 0,58 & 0,90 & 1,12 & 1,24 & 1,32 & 1,41 & 1,45 & 1,49 & 1,51 & 1,48 & 1,56 & 1,57 & 1,59 \\
\hline
\end{tabular}

Indeks konsistensi kemudian diubah dalam bentuk rasio inkonsistensi dan membaginya dengan random index (RI). Perbandingan antara CI dan RI untuk suatu matriks didefinisikan sebagai consintency ratio(CR) yang ditunjukkan dalam persamaan:

$$
C R=\frac{C I}{R I} \leq 0,1
$$

Isue Aksesibilitas dan Pengembangan Wilayah Sebagai Kriteria Penentu Prioritas Peningkatan Jalan di Kabupaten Pidie Jaya - Ahmad Irvan Antony Has, Renni Anggraini, Alfa Taras Bulba 
Dari pembobotan nilai kriteria pada setiap responden, maka dihitung nilai rata-rata eigen kriteria dan dihitung nilai rata-rata eigen alternatif. Untuk mendapatkan hasil urutan prioritas maka dihitung dengan menggunakan system matematika menurut (P.S. Brodjonegoro, 1991) dengan persamaan:

$Y=A\left(a_{1}\right.$.bobot $a_{1}+. .+a_{5}$. bobot $\left.a_{5}\right)+. . D\left(d_{1}\right.$. bobot $d_{1}+. .+d_{5}$. bobot $\left._{5}\right)(6)$

Dari hasil tahapan analisis data didapatkan hasil urutan kriteria dan urutan alternatif peningkatan jalan berdasarkan penilaian responden atau stakeholders pada criteria aksesibilitas dan pengembangan wilayah di KabupatenPidie Jaya.

\section{Hasil dan Pembahasan}

Dari hasil penelitian ini penentuan criteria dominan, alternatif dominan pada kriteria dan urutan prioritas peningkatan jalan di Kabupaten Pidie Jaya berdasarkan aksesibilitas dan pengembangan wilayah. Dapat dijelaskan sebagai berikut.

\subsection{Penilaian Bobot Kriteria}

Dari analisis yang dilakukan menunjukkan data seperti diperlihatkan pada Tabel 4.

Tabel 4 Bobot nilai criteria

\begin{tabular}{ccccccccc}
\hline \multirow{2}{*}{ No. } & \multirow{2}{*}{ Kriteria } & \multicolumn{5}{c}{ Responden } & Jumlah & \multirow{2}{*}{ Bobot } \\
\cline { 3 - 7 } & & R1 & R2 & R3 & R4 & R5 & Nilai Eigen & \\
\hline 1 & K1 & 0,250 & 0,500 & 0,500 & 0,667 & 0,667 & 2,584 & 0,517 \\
\hline 2 & K2 & 0,750 & 0,500 & 0,500 & 0,333 & 0,333 & 2,417 & 0,483 \\
\hline & Jumlah & 1,000 & 1,000 & 1,000 & 1,000 & 1,000 & & 1,000 \\
\hline
\end{tabular}

Tabel 4 memperlihatkan bahwa kriteria K1 lebih dominan dibanding kriteria K2. Nilai bobot criteria yang dominan pada criteria K1, yaitu criteria aksesibilitas sebesar 0,517. Hal ini menunjukkan bahwa criteria dominan yang perlu dipertimbangkan dalam penentuan peningkatan jalan di Kabupaten Pidie, dibandingkan kriteria K2, yaitu pengembangan wilayah dengan nilai bobot sebesar 0.483. Kriteria aksesibilitas memegang peranan penting dalam upaya perkembangan wilayah sebab tanpa di dukung oleh system transportasi, sarana dan prasarana transportasi yang memadai, maka perkembangan suatu daerah akan sulit berkembang (Ramli et al., 2017).

\subsection{Penilaian Bobot Alternatif}

Pada tahapan ini nilai bobot alternative dapat diterima apabila nilai ratio konsitensi bernilai $\mathrm{CR}<0.1$, pada penelitian ini nilai rata-rata ratio konsitensi bernilai 0,03 . Penilaian bobot alternative peningkatan jalan dapat disimpulkan bahwa setiap criteria mempunyai alternative tersendiri yang perlu diprioritaskan dalam peningkatan jalan di Kabupaten Pidie Jaya sesuai pada Gambar2 memperlihatkan bila dilihat dari criteria aksesibilitas, peningkatan jalan yang perlu diprioritaskan adalah Jalan Simpang Pertanian-Cot Trieng-Rungkom (A3) dengan nilai bobot sebesar 0,647. Pada criteria pengembangan wilayah, peningkatan jalan yang perlu diprioritaskan adalah Jalan Trienggadeng-Panton Beurasan - Cubo (A4) dengan nilai bobot sebesar 0,527.

Isue Aksesibilitas dan Pengembangan Wilayah Sebagai Kriteria Penentu Prioritas Peningkatan Jalan di Kabupaten Pidie Jaya - Ahmad Irvan Antony Has, Renni Anggraini, Alfa Taras Bulba 


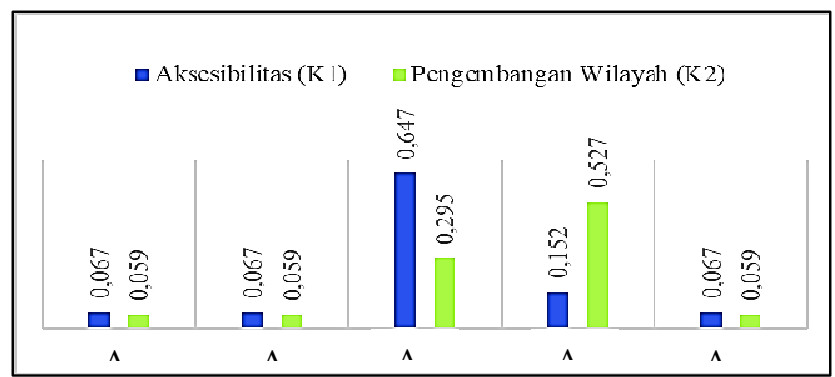

Gambar 2 Bobot alternative dilihat dari kriteria

\subsection{UrutanPrioritasPeningkatan Jalan}

Dari data penilaian bobot alternative di atas, maka dapat ditentukan urutan prioritas alternative berdasarkan criteria aksesibilitas dan pengembangan wilayah. Untuk menentukan hasil urutan prioritas peningkatan jalan, maka dilakukan perhitungan dengan menggunakan model matematik yang dihitung dengan system persamaan matemtika (P.S. Brodjonegoro, 1991). Nilai bobot urutan prioritas peningkatan dapat dilihat pada Tabel 5.

Tabel 5 Urutan Prioritas Alternatif

\begin{tabular}{cccccc}
\hline \multirow{2}{*}{ No. } & \multirow{2}{*}{ Alternatif } & \multicolumn{2}{c}{ Kriteria } & Jumlah & \multirow{2}{*}{ Urutan } \\
\cline { 3 - 4 } & & K1 & K2 & Bobot & \\
\hline 1 & A1 & 0,067 & 0,059 & 0,063 & 3 \\
\hline 2 & A2 & 0,067 & 0,059 & 0,063 & 3 \\
\hline 3 & A3 & 0,647 & 0,295 & 0,477 & 1 \\
\hline 4 & A4 & 0,152 & 0,527 & 0,333 & 2 \\
\hline 5 & A5 & 0,067 & 0,059 & 0,063 & 3 \\
\hline & Jumlah & 1,000 & 1,000 & 1,000 & \\
\hline Nilai bobot kriteria & 0,517 & 0,483 & & \\
\hline
\end{tabular}

\section{Kesimpulan dan Saran}

\subsection{Kesimpulan}

Berdasarkan dari hasil penelitian ini maka dapat disimpukan bahwa dalam penentuan prioritas peningkatan jalan di Kabupaten Pidie Jaya, kriteria yang perlu dipertimbangkan antara aksesibilitas dan pengembangan wilayah adalah aksesibilitas dengan nilai eigen rata-rata sebesar 0,517. Sedangkan prioritas utama alternatif peningkatan jalan yang lebih dominan dengan jumlah nilai 0,477 adalah Jalan Simpang Pertanian-Cot Trieng-Rungkom (A3), dan prioritas keduaa dalah Jalan Trieng gadeng-Panton Beurasan-Cubo (A4) dengan jumlah nilai 0,333. Alternatif peningkatan jalan yang lainnya bernilai sama, sehingga sama-sama berada pada prioritas ketiga.

\subsection{Saran}

Disarankan bagi peneliti selanjutnya yang melakukan penelitian relevan hendaknya dalam menentukan sampel terlebih dahulu menentukan karakteristik responden, agar hasil data kuesioner yang dikumpulkan lebih berkualitas untuk dianalisis melalui metode pengambilan keputusan. Dengan menambahkan kriteria yang sesuai dengan issue setempat akan memperkuat hasil yang dicapai pada penelitian.

Isue Aksesibilitas dan Pengembangan Wilayah Sebagai Kriteria Penentu Prioritas Peningkatan Jalan di Kabupaten Pidie Jaya - Ahmad Irvan Antony Has, Renni Anggraini, Alfa Taras Bulba 


\section{Daftar Kepustakaan}

A.K. Mahi, 2016. Pengembangan Wilayah: Teori dan Aplikasi. Kencana, Jakarta. Afriansyah, R., Wicaksono, A., Djakfar, L., 2012. Penentuan Prioritas Pengembangan Jaringan Jalan Pendukung Kawasan Strategis di Pulau Sumbawa. J. Rekayasa Sipil 6.

Agus Taufik Mulyono, 2010. Model Monitoring Dan Evaluasi Pemberlakuan Standar Mutu Perkerasan Jalan Berbasis Pendekatan Sistemik. Universitas Diponegoro, Semarang.

Dinas Pekerjaan Umum Kabupaten Pidie Jaya, 2020. Usulan Dana Alokasi Khusus (DAK) Fisik tahun 2021 Bidang Jalan. Meureudu.

Irawan, H., Ismiyati, I., Pudjianto, B., 2016. Penentuan Skala Prioritas Penanganan Jalan Kabupaten di Kabupaten Kudus Dengan Metode Analytical Hierarchy $\quad$ Process. 37. https://doi.org/10.14710/teknik.v37i2.8411

P.S. Brodjonegoro, 1991. Petunjuk Mengenai Teori dan Aplikasi dari Model The Analytic Hierarchy Process. Sapta Utama, Jakarta .

Pemerintah Kabupaten Pidie Jaya,. Qanun RPJMK Pidie Jaya 2019 - 2024. Indonesia.

Pemerintah Republik Indonesia, 2006. Peraturan Pemerintah Nomor 34 Tahun 2006 Tentang Jalan. Lembaran Negara Republik Indones. Tahun 2006 Nomor 86.

Ramli, M., Saleh, S.M., Anggraini, R., 2017. Studi Pengembangan Jaringan Jalan Pendukung Rencana Induk Pelabuhan (RIP) di Provinsi Aceh. J. Tek. Sipil Univ. Syiah Kuala 1, 143-156.

S. Fatimah, 2019. Teori Perencanaan. Uwais Inspirasi Indonesia, Ponorogo.

Saaty, T.L., 1993. Pengambilan keputusan bagi para pemimpin. Jakarta, PT. Pustaka Binaman Press.

Sushera, V., Rohman, M.A., Gde Kartika, A.A., 2019. Analisis Prioritas Pemeliharaan Jalan Kabupaten Karanganyar Metode Analytical Hierarchy Process (AHP). J. Transp. Sist. Mater. dan Infrastruktur 1. https://doi.org/10.12962/j26226847.v1i2.5033

Ulwan, M.N., 2014. Teknik Pengambilan Sampel dengan Metode Purposive Sampling. Retrieved December. 